\title{
Simultaneous Quantification of Quercetin and Syringic Acid in Methanolic Extract of Leucas lavandulifolia by using Validated HPTLC- Densitometric Method
}

\author{
Pushpendra Kumar Shukla, Akanksha Srivastava, Ankita Misra, Sharad Srivastava* \\ Pharmacognosy and Ethnopharmacology Division, CSIR-National Botanical Research Institute, Lucknow, Uttar Pradesh, INDIA.
}

\begin{abstract}
A simple, sensitive and reliable High Performance Thin Layer Chromatography (HPTLC) method was developed for the simultaneous quantification of bioactive compounds i.e quercetin and syringic acid in Leucas lavandulifolia. Methanolic extract used on HPTLC silica gel $60 \mathrm{~F} 254,10 \times 10$ (Mark) plate for the separation and quantification of bioactive compounds by using toluene: ethyl acetate: formic acid (7: 2.5: $0.5 \mathrm{v} / \mathrm{v}$ ) as mobile phase. The used mobile system gives well-resolved bands of quercetin (Rf value 0.32 $\pm 0.06)$ and syringic acid $\left(R_{f}\right.$ value $\left.0.38 \pm 0.05\right)$ in the extract of $L$. lavandulifolia. The correlation coefficient was found to be 0.987 and 0.997 with standard deviation of 667.77 and 3819.77 for quercetin and syringic acid. The accuracy of the method was confirmed by recovery studies at different levels using the standard addition method. Precision studies (both inter day and intraday) are within the standard limit, RSD (\%) is less than $3 \%$. The average recovery of quercetin and syringic acid was $100.02 \%$ and $100.13 \%$ suggesting the accurateness of the method. The quantification of quercetin and syringic carried out by using a densitometric absorption mode at $275 \mathrm{~nm}$ and 370 $\mathrm{nm}$ respectively. The developed method was validated and found to be specific, linear and accurate with precision and accuracy in the concentration range of $2.0-6.0 \mu \mathrm{g} / \mathrm{spot}$ for quercetin and syringic acid. Hence, simple, reproducible and selective HPTLC method has been developed for the estimation of the identified bioactive markers which may be utilized as a tool for the proper authentication and standardization of L. lavandulifolia.
\end{abstract}

Key words: HPTLC, Leucas lavandulifolia, Quercetin, Syringic acid, DPPH, Hydroxyl Radical-Scavenging.

\section{INTRODUCTION}

Nature has provided us a huge amount of remedies to heal illness of human being. In today's scenario, there is an increasing interest in herbal medicines accompanied by increased research investigation into the pharmacological properties of phytochemical ingredients and their capacity to treat various types of diseases. ${ }^{1,2}$ A number of drugs have been entered in the international market which had been previously used in ethanomedicine and traditional medicine. Although, scientific study have been carried out on a large scale to provide the evidence-based therapeutics data for the authentication and validation of ayurvedic drugs. In the Indian context, 43 species of genus Leucas are available, generally shrubs, sub-shrubs, annual herbs, or perennial herbs with woody root and/or stem base. ${ }^{3}$ The genus Leucas lavandulifolia Sn. (Lamiaceae) has been widely in use by the traditional healers to cure many diseased which shows that this genus has huge potential for the discovery of new drugs. The Leucas lavandulifolia (Leucas indica) commonly known as Gumo (Hindi), Halkusa (Bengali) is a very well known medicinal plant in Indian system of
Submission Date: 28-05-2020; Revision Date: 14-07-2020; Accepted Date: 13-08-2020

DOI: 10.5530/ijper.54.3s.169 Correspondence: Dr. Sharad Srivastava Pharmacognosy and Ethnopharmacology Division, CSIR-National Botanical Research Institute, Lucknow-226001, Uttar Pradesh, INDIA.

Phone: +91 0522-2297818 E-mail: sharad_ks2003@ yahoo.com

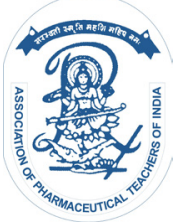

www.ijper.org 
medicine from time immemorial. ${ }^{4}$ It is a herbaceous, annual weed, $30-80 \mathrm{~cm}$ tall, found in grazing land, wasteland and in roadside areas ${ }^{5}$ (Anonyomous, 1962) and it is widely distributed throughout Bangladesh, Sri Lanka, Nepal, Myanmar, Thailand, Malaysia, Indonesia to new Guinea, China, tropical American countries and India. In India it is found in Bihar, UP Andhra Pradesh, Kerala and Tamil Nadu. ${ }^{6}$

Various phytochemicals in Leucas lavandulifolia were also reported such as linifolioside, isopimarane rhamnoglucoside, leupol, taxaxerone and chrysoeriol-6. Evaluation of tincture in $L$. lavandulifolia was characterized by examination of co-chemical properties of L. lavandulifolia (Arial part). Some phytochemical such as acacetin, chrysoeriol were also investigated in chloroform and diethyl extract of the species. ${ }^{7,8}$

Traditionally, it has been extensively used by rural people of Bihar especially in Mithila region, past of tender shoots is applied to relieve headache, leaf juice used to treat stomach complaints, poisonous insect bites, skin diseases, scorpion sting, cough and cold. ${ }^{9}$ The local tribes of Orissa used this plant as a vegetable. The juice of the plant is used in the treatment of malarial fever. ${ }^{10}$ Whole plant powders of Leucas lavandulifolia and Wattakaka volubilis are mixed with water and orally administered thrice a day for curing paralysis and fits. Pharmacologically, L. lavandulifolia is used in antitussive, wound healing, hypoglycaemic, ${ }^{11}$, ${ }^{12}$ anti-inflammatory and antibacterial, ${ }^{13}$ as reported in the literature. The phytochemical analysis shows the presence of carbohydrate, alkaloids, steroids, flavonoids, triterpenoids, essential oil, saponins and tannins. ${ }^{14-16}$ Apart from this isopimarane rhamnoglucoside, linifolioside, linifoliol, ${ }^{17}$ lupeol, taraxerone have been isolated from the aerial parts of the species. ${ }^{18}$

In view of its diverse therapeutic efficacy and traditional use in India, it was desirable to fix some pharmacognostical parameters for future identification of the drug materials to explore its different phytochemical constituents. In the present study, we are focusing on identification and quantification of quercetin and syringic acid in Leucas lavandulifolia and evaluation of its antioxidant potential. This study will be helpful in the authentication and identification of the particular plant used as a drug in pharmaceutical industries.

\section{MATERIALS AND METHODS}

\section{Plant material}

Collection of Leucas lavandulifolia was done in September 2014 from Tamiya, Madhya Pradesh, India. Plant material was identified and authenticated by Dr. Sharad Srivastava, Senior Principal Scientist Pharmacognosy division, CSIR-NBRI, Lucknow. Plant specimen was assigned a voucher number (LWG No. 254034) and deposited in the institute's repository. Arial parts were washed, shade dried and powdered (40 mesh) using an electric grinder (Figure 1).

\section{Chemicals}

Toluene, ethyl acetate, methanol, formic acid (MP biomedical Ltd.) and HPTLC precoated silica gel 60 $\mathrm{GF}_{254}(10 \times 10 \mathrm{~cm})$ plates (Merck, India) was used. Ascorbic acid, quercetin, rutin, BHT (Butylated hydroxy toluene) and 1-1-diphenyl-2-pic-rylhydrazyl (DPPH), 2-deoxy ribose sugar, Quercetin (95\%), syringic acid $(97 \%)$ were purchased from Sigma-Aldrich. All other chemical were purched from SD fine chemicals.

\section{Extraction protocol for Quercetin and Syringic acid}

The coarsely powdered aerial parts of Leucas lavandulifolia (2 gm) were macerated with methanol for $24 \mathrm{hrs}$ at room temperature $\left(25 \pm 2^{\circ} \mathrm{C}\right)$. Extraction repeated thrice, filter and pooled filtrate was dried in rotatory evaporator (Buchi, USA) under standard conditions of temperature $\left(55 \pm 2^{\circ} \mathrm{C}\right)$, pressure $(40 \mathrm{mbar})$ and then lyophilized (Labconco, USA). The extractive yields were calculated $368 \mathrm{mg}$ on a dry weight basis.

\section{Chromatographic Conditions}

A stock solution of sample and the markers of strength $10 \mathrm{mg} / \mathrm{mL}$ and $1 \mathrm{mg} / \mathrm{mL}$ respectively were prepared in methanol. Working solution of sample $(1.0 \mathrm{mg} /$ $\mathrm{mL}$ ) and standards (quercetin and syringic acid) (0.1 $\mathrm{mg} / \mathrm{mL}$ ) were freshly prepared from stock solution for analytical work. The spot was applied as $8 \mathrm{~mm}$ wide bands positioned $12 \mathrm{~mm}$ from the bottom and $18 \mathrm{~mm}$ from the side of the plate, using CAMAG Automated TLC Sampler 4 (ATS 4) with nitrogen flow providing a delivery speed of $150 \mathrm{nl} / \mathrm{s}$ from application syringe. These conditions were kept constant throughout the analysis of samples. The plate was developed in a CAMAG Automatic Developing Chamber (ADC) by using standard developing condition, 30 min saturation time of the chamber, controlled humidity $\mathrm{MgCl}_{3}$, $33 \% \mathrm{RH}), 25^{\circ} \mathrm{C}$ room temperature, $85 \mathrm{~mm}$ solvent run from bottom to top of the plate, by putting $10 \mathrm{~mL}$ tertiary mobile phase (solvent system) in the ratio of toluene: ethyl acetate: formic acid $(7: 2.5: 0.5 \mathrm{v} / \mathrm{v})$ on twin trough developing chamber $(20 \times 10 \mathrm{~cm}) .10$ min TLC plate was dried and scanned by using densitometory CAMAG TLC scanner equipped with Vision Cats software (slit width, $5 \mathrm{~mm} \times 0.30 \mathrm{~mm}$ ) in absorption reflection mode. 
The quantification of quercetin and syringic acid were carried out using a densitometric absorption mode at $275 \mathrm{~nm}$ and $370 \mathrm{~nm}$ (Figure 2 and 3).

\section{Method validation}

HPTLC method validation includes evaluation of linearity, sensitivity, precision, selectivity and robustness parameters according to the ICH guidelines, 2005, to access the performance of the method. ${ }^{19}$

\section{Linearity}

Different dilutions were spotted in triplicate on TLC plate concentrations of $2,4,6, \mu \mathrm{g}$ per spot of quercetin and syringic acid (Table 1). The data of peak area versus concentration were treated by the linear leastsquare regression equation. The slope, intercept and correlation coefficient for the calibration curve were determined with 3 different concentrations. The results are expressed as a percentage of the total area of identified compounds. Based on the calibration curve quercetin and syringic acid content was estimated in the plant and expressed on a dry weight basis.

\section{Sensitivity}

The sensitivity of the method was determined with respect to Limit of Detection (LOD) and Limit of Quantification (LOQ). It was calculated are as signal noise ratios 3:1 and 10:1 (Table 1).

\section{Stability}

The reproducibility of the method was determined by analyzing standard of single concentration $(0.1 \mathrm{mg} / \mathrm{mL})$ over three times on the same day. The relative standard deviation was used to evaluate the reproducibility of the method within the limit of the standard. The developed method was also validated for selectivity, specificity and resolution of the analytic (Table 1).

\section{Precision}

Interday and intraday studies were carried out to test the precision of method and expressed as the relative standard deviation (\%). Intraday repeatability was tested by injecting sample solution of individual population three times a day. Similarly, interday repeatability was assessed over three consecutive days by using same concentration (of the sample), thrice a day (Table 3).

\section{Accuracy}

The accuracy (standard addition method) of the methods was determined by analyzing the percentage recoveries and mean RSD (\%) of standard quercetin and syringic acid in the collected samples (Table 4). The samples were spiked with three different concentrations:
50, 100 and $150 \mu \mathrm{g}$. The spiked samples were recovered in triplicate and then analyzed by developed the HPTLC method.

\section{Robustness}

Robustness is evaluation of the method to stay unaltered by small but deliberate variations in the experiential conditions, which indicate of the reliability of the method. It was achieved by introducing small variations in chromatographic parameters, such as small variations in the ratio of the mobile phase, the time gaps between spotting to chromatography and from chromatography to scanning and the time interval between drying and scanning

\section{In-vitro Antioxidant Activity}

Antioxidant potential of Leucas lavandulifolia was determined by DPPH radical scavenging assay ${ }^{2-}$ and Hydroxyl Radical-Scavenging Activity. ${ }^{21}$

\section{Statistical analyses}

Observations of each sample were performed in triplicate. The data were recorded as mean \pm standard

\begin{tabular}{|c|c|c|c|}
\hline SI.No. & Parameter & Quercetin & Syringic acid \\
\hline 1 & $\begin{array}{l}\text { Linearity range } \\
\text { (ng/spot) }\end{array}$ & $2000-6000$ & $2000-6000$ \\
\hline 2 & $\operatorname{Rf}(\mathrm{cm})$ & 0.32 & 0.41 \\
\hline 3 & $\lambda_{\max }$ & $275 \mathrm{~nm}$ & $370 \mathrm{~nm}$ \\
\hline 4 & $\begin{array}{l}\text { Regression } \\
\text { Equation }\end{array}$ & $\begin{array}{c}y=329650 x+ \\
28720\end{array}$ & $\begin{array}{c}y=329650 x+ \\
28720\end{array}$ \\
\hline 5 & $\begin{array}{l}\text { Correlation } \\
\text { coefficient }\end{array}$ & 0.987 & 0.997 \\
\hline 6 & $\begin{array}{c}\text { Regression } \\
\text { coefficient }\end{array}$ & 0.9748 & 0.9952 \\
\hline 7 & Average & 30038.57 & 17730.8 \\
\hline 8 & Slope & 329.65 & 1905.32 \\
\hline 9 & Standard deviation & 667.77 & 3819.776 \\
\hline 10 & Standard error & 149.99 & 373.1798 \\
\hline 11 & LOD ( $\mu \mathrm{g} / \mathrm{spot})$ & 20.25 & 102.36 \\
\hline 12 & LOQ ( $\mu \mathrm{g} / \mathrm{spot})$ & 6.68 & 33.77 \\
\hline 13 & Intercept & 28719.97 & 10109.5 \\
\hline
\end{tabular}

Table 2: Quantification of quercetin and syringic acid
in Leucas lavandulifolia.

$n=3, \pm S D$ (Standard deviation) 
deviations and analysis of variance (ANOVA) was used to calculate the critical $\mathrm{f}$ value ( $t$-test) and the statistical significance for the analyzed of quercetin and syringic acid content by Graph Pad Prism (Graph Pad Software Inc., San Diego, CA, USA). The significance of the regression coefficients was evaluated by $\mathrm{f}$ test. Differences were considered significant at $P<0.05$.

\section{RESULTS AND DISCUSSION}

\section{Calibration}

Calibration curve was achieved by using linearity range $2000-6000 \mathrm{ng} / \mathrm{spot}$ with equation $\mathrm{y}=329.65 \mathrm{x}+28720$, regression coefficient $\left(R^{2}\right)=0.9748$ and $y=1905.3 x+$ 10110, regression coefficient $\left(\mathrm{R}^{2}\right)=0.9952$ of quercetin and syringic acid respectively. Slope and standard deviation of quercetin and syringic acid was found 329.65, 1905.32 and 667.77, 3819.776 respectively (Table 1). LOD (3:1) and LOQ (10:1) values were within the limit of acceptance. Other statistical parameters were in accordance with $\mathrm{ICH}$ guidelines.

\section{Quantification of marker compounds}

As per the previous studies, bioactive compounds are mainly responsible for the biological potential of any species. ${ }^{22-24}$ Thus, to validate the claim it is necessary to identify and quantify the bioactive markers which confirm the potential of the species. For this, simple, accurate and stable HPTLC chromatography method was developed for the quantification of quercetin and syringic. The mobile phase used for the separation of quercetin and syringic acid is toluene: ethyl acetate: formic acid $(7: 2.5: 0.5 \mathrm{v} / \mathrm{v})$, shows the proper separation and better visibility in the UV-light compare to the other mobile phases which has been reported in earlier studies. Bands for the quercetin and syringic acid present in the samples were compared with the $\mathrm{R}_{f}$ value and the UV spectra of the marker compounds (Figure 2 and 3). The $\mathrm{R}_{f}$ value of these markers was found $(0.32 \pm 0.002)$ for quercetin and in $(0.31 \pm 0.003)$ for syringic acid. The dry weight percentage of the marker compounds viz quercetin $(0.15 \pm 0.002) \%$ dry weight and syringic acid $(0.45 \pm 0.005) \%$ dry weight present in the aerial parts of Leucas lavandulifolia respectively (Table 2).

\section{Method validation}

The method was calibrated at three different dilutions of quercetin and syringic acid (200, 400 and $600 \mathrm{ng} /$ spot $)$ with linear regression equation $\{(y=329650 x+$ $28720)$ and $(y=329650 x+28720)$ respectively $\}$ and regression coefficient $\mathrm{t}(0.9748$ and 0.9952 respectively)

\begin{tabular}{|c|c|c|c|c|c|c|c|c|}
\hline \multirow{3}{*}{$\begin{array}{l}\text { Concentration (ng } \\
\text { spot }^{-1} \text { ) } \\
\text { Amount of Standard }\end{array}$} & \multicolumn{4}{|c|}{ Quercetin } & \multicolumn{4}{|c|}{ Syringic acid } \\
\hline & \multicolumn{2}{|c|}{ Intra Day } & \multicolumn{2}{|c|}{ Inter Day } & \multicolumn{2}{|c|}{ Intra Day } & \multicolumn{2}{|c|}{ Inter Day } \\
\hline & SD & \%RSD & SD & \%RSD & SD & \%RSD & SD & \%RSD \\
\hline 2000 & 5.139 & 0.017 & 06.472 & 0.0237 & 18.449 & 0.1342 & 11.296 & 0.081 \\
\hline 4000 & 7.807 & 0.026 & 13.016 & 0.0248 & 12.232 & 0.067 & 20.177 & 0.104 \\
\hline 6000 & 18.79 & 0.061 & 09.013 & 0.0196 & 35.652 & 0.167 & 13.697 & 0.0632 \\
\hline
\end{tabular}

$n=3, \pm S D$ (Standard deviation)

Table: 4 Result and statistical data for recovery studies for quercetin and syringic acid in Leucas lavandulifolia.

\begin{tabular}{|c|c|c|c|c|c|c|c|c|c|c|c|c|}
\hline $\begin{array}{l}\frac{0}{0} \\
\text { हू } \\
\text { ळ }\end{array}$ & 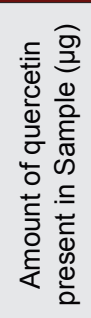 & 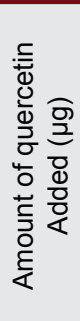 & 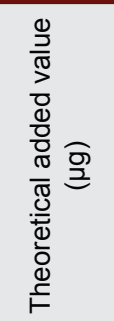 & 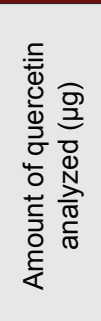 & 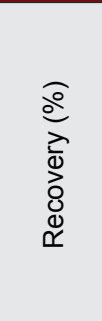 & 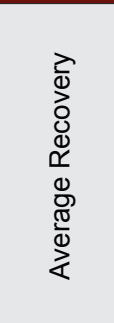 & 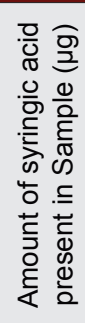 & 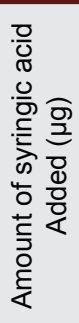 & 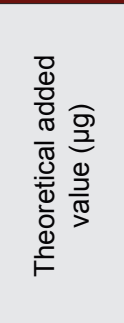 & 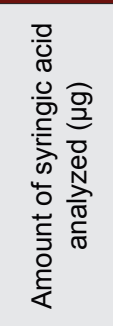 & 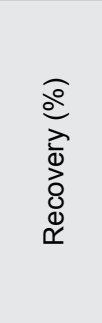 & 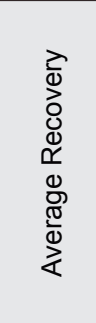 \\
\hline \multirow{3}{*}{ 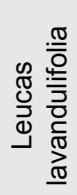 } & 0.088 & 50 & 50.088 & 50.095 & 100.01 & \multirow{3}{*}{100.016} & 0.473 & 50 & 50.473 & 50.481 & 100.01 & \multirow{3}{*}{100.13} \\
\hline & 0.088 & 100 & 100.088 & 100.12 & 100.03 & & 0.473 & 100 & 100.473 & 100.631 & 100.15 & \\
\hline & 0.088 & 150 & 150.088 & 150.11 & 100.01 & & 0.473 & 150 & 150.473 & 150.824 & 100.23 & \\
\hline
\end{tabular}

$n=3, \pm S D$ (Standard deviation) 
were obtained respectively (Table 1). Calibration curve for quercetin and syringic acid (area vs. concentration) shows the positive random pattern, indicating that a linear model provides a decent fit to the data.

According to the ICH guidelines, 2005 various parameters vir. the limit of detection (LOD), the limit of quantification (LOQ), linearity, sensitivity, precision, selectivity and robustness were studies to validate the method. LOD (3:1) and LOQ (10:1) values are within the limit of acceptance. Other statistical parameters are in accordance with ICH guidelines as shown in (Table 3 and Table 4). Stability of method was evaluated by repeated $(n=3)$ analysis of standard at single level $(0.1 \mathrm{mg} / \mathrm{mL})$, standard deviation (667.77, 3819.77), standard error (329.65, 1905.32) and intercept $(28719.97,10109.5)$ reveals that method is stable under chromatographic conditions. For specificity, UV spectrum of samples was analyzed and, was found to be superimposed over the reference standard and peak was obtain at same $\mathbf{R}_{f}$ (Figure 3). The peak purity of these compounds was also assessed by comparing the spectra at three points' viz., peak start, peak apex and peak end positions (Figure 4) Precision validation of method was analyzed by interday and intraday repeatability studies at single level using

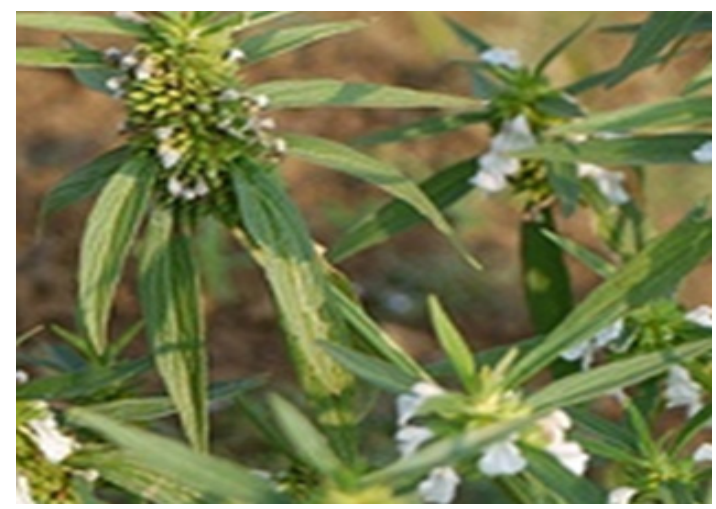

Figure 1: A flowering twig of Leucas lavandulifolia.

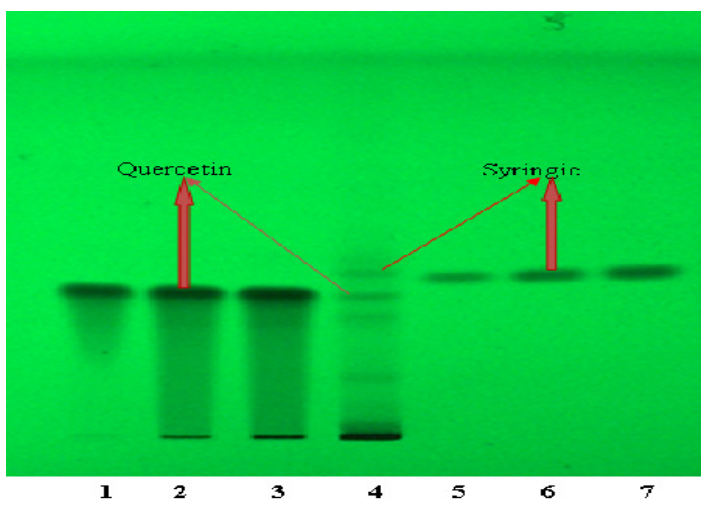

Figure 2: HPTLC fingerprinting of Leucas lavandulifolia at $254 \mathrm{~nm}$.

Abbreviation: 1-3 Quercetin, 4- Leucas lavandulifolia, 5-7 Syringic acid fixed concentration $(0.1 \mathrm{mg} / \mathrm{mL})$ of standard solution. RSD (\%) values as shown in are observed within the limit i.e. NMT $5 \%$. Accuracy is tested through standard addition method by spiking of samples at three different levels of 50, 100 and $150 \%$ (Table 3). Recovery of analyte shows the variation from 100.03 to $100.01 \%$ (quercetin) and 100.23 to $100.01 \%$ (syringic acid), which are in the acceptance limit of $95-105 \%$ and hence the method was found to be accurate and precise also (Table 4). Method robustness is tested by deliberate variations in the method conditions and indicates the reliability of the method for the robustness study, different mobile phase compositions and injection times were assessed. Developed HPTLC method is simple, reliable, accurate and reproducible for the quantification of targeted marker compounds.

\section{In-vitro assay}

\section{In-vitro antioxidant potential}

In previous study, phenolic and flavonoid compounds demonstrated high antioxidant potential in various in vitro and in vivo systems. ${ }^{25}$ By using these compounds, plants developed effective defense mechanism of the system against harmful effects, to protect from visible

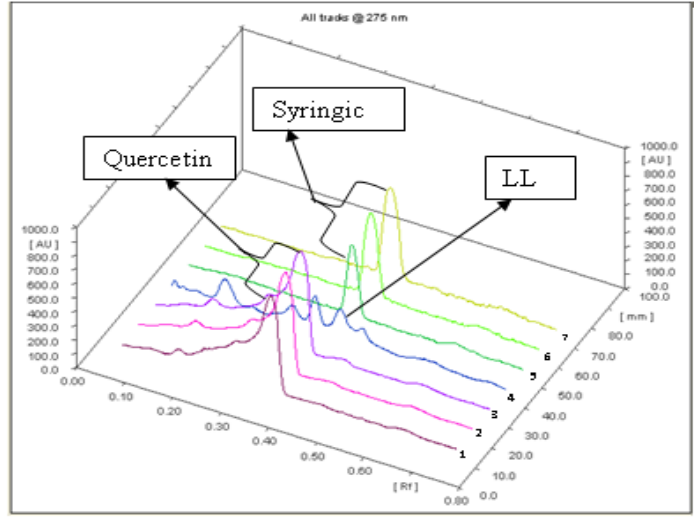

Figure 3: 3D Densitometry analysis of Leucas lavandulifolia.

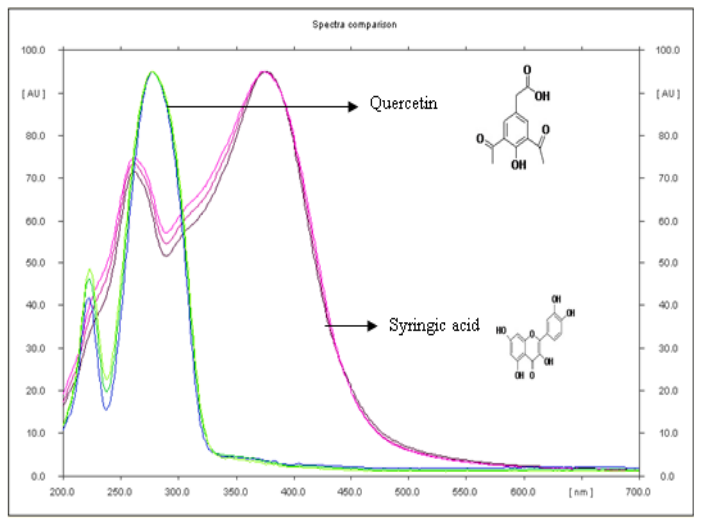

Figure 4: Purity Spectral analyses of quercetin and syringic acid. 


\begin{tabular}{|c|c|c|}
\hline \multicolumn{3}{|c|}{ Table 5: Phytochemical analysis of } \\
Leucas lavandulifolia.
\end{tabular}

$n=3, \pm S D$ (Standard deviation)

and invisible aspects. ${ }^{26,27}$ Quercetin and Syringic acid are phenolic compounds which prevent the endogenous formation of free radicals which ensured by the spatial separation of the process in which free radicals are formed. ${ }^{28}$ It also inhibits xanthine oxidases (XOD) which have the ability to capture superoxide radicals. It also helps in the treatment of other diseases such as gout and ischemia by reducing uric acid and superoxide radical. ${ }^{29}$

Total phenolic and flavonoid analysis was performed in the aerial part of Leucas lavandulifolia which shows phenolic content (TPC) $5.6 \pm 0.004\{(\mathrm{mg} / \mathrm{g}) * \mathrm{GAE}\}$ and total flavonoid content (TFC) $4.22 \pm 0.007\{(\mathrm{mg} / \mathrm{g})$ $* \mathrm{QE}\}$ (Table 5). Previous antioxidant study of Leucas species shows that ethanolic extract has huge potential against DPPH and free radical scanning assay and data directly correlated with phenolic and flavonoid content. ${ }^{30-31}$ In our previous study, four Lencas species (L. aspera, L. biflora, L. cristata and L. mollissima) aerial part were analyzed and found that $L$. aspera have highest phenolic and flavonoid content among of them. ${ }^{32}$ In present investigation, in vitro antioxidant activity was evaluated by DPPH and deoxyribose method. Data reveals that activity increases linearly with concentration, i.e., $0.1-0.5 \mathrm{mg} / \mathrm{mL}$ of tested plant extract. $\mathrm{IC}_{50}$ value found as followed by $(404.1 \pm 0.003)$ and $(9.601 \pm 0.033)$ in DPPH and deoxyribose assay respectively (Table 6). Pharmacological potential of the plant mainly depend on the quantity of the bioactive compounds which ultimately directly affect the potential of the species. In our previous investigation, four Leucas species were selected to find out the best antioxidant potent of the species. In this, Leucas aspera shows high phenolic and flavonoid content along with antioxidant potential. In present investigation, Leucas lavandulifolia shows more phenolic, flavonoid content and antioxidant potential, compared to the L. aspera. Within the confinement of our study, we conclude that L. lavandulifolia showed excellent antioxidant potential with reference to other species L. aspera, L. biflora, L. cristata and L. mollissima. Therefore, this study may be helpful in future for the selection of potential Leucas species and also may be

\begin{tabular}{|c|c|c|c|}
\hline$S / N$ & Plant/standard & $\begin{array}{c}\text { DPPH }\left\{\begin{array}{c}\left\{\mathrm{C}_{50}(\boldsymbol{\mu g} /\right. \\
\mathrm{mL})\}\end{array}\right.\end{array}$ & $\begin{array}{c}\text { Deoxy ribose } \\
\text { assay }\left\{\mathrm{IC}_{50}(\mu \mathrm{g} /\right. \\
\mathrm{mL})\}\end{array}$ \\
\hline 1 & $\begin{array}{l}\text { Leucas } \\
\text { lavandulifolia }\end{array}$ & $404.1 \pm 0.003$ & $9.601 \pm 0.033$ \\
\hline 2 & Quercetin & $06.04 \pm 0.122$ & $07.55 \pm 0.021$ \\
\hline 3 & Syringic acid & $05.241 \pm 0.173$ & $06.52 \pm 0.074$ \\
\hline 4 & Ascorbic acid & $3.86 \pm 0.057$ & $10.37 \pm 0.057$ \\
\hline
\end{tabular}

$n=3, \pm$ SD (Standard deviation)

used as alternative species in preparation of ayurvedic formulations.

\section{CONCLUSION}

Essential metabolites are present in considerable amount viz- flavonoids, phenolics which supports the in-vitro biological screening and establishes standards of L. lavandulifolia. The HPTLC analysis confirms the quantitative determination of bioactive metabolites in the plant. Quercetin is a flavonoid whereas the syringic acid is a phenolic component both shows the antioxidant property and in L. lavandulifolia the percentage of quercetin, as well as the syringic acid, is present in a good amount, which was not reported in previous literature. These types of studies on natural products are designed to establish the importance of medicinal properties of plants by correlating with the traditional uses and scientific knowledge to discover the active potential drug which will utilize by the pharmaceutical industries.

\section{ACKNOWLEDGEMENT}

The authors are thankful to the Director, CSIR-National Botanical Research Institute, Lucknow for providing necessary facilities during the course of the experiment. (MS no “CSIR-NBRI_MS/2020/05/16”).

\section{CONFLICT OF INTEREST}

The authors declare that there are no conflicts of interest.

\section{REFERENCES}

1. Thomford N, Senthebane D, Rowe A, Munro D, Seele P, Maroyi A, et al. Natural products for drug discovery in the $21^{\text {st }}$ century: Innovations for novel drug discovery. Int J of Mol Sci. 2018;19(6):1578.

2. Patra JK, Das G, Fraceto LF, Campos EV, DelRodriguez-Torres MP, AcostaTorres LS, et al. Nano based drug delivery systems: Recent developments and future prospects. J of Nanobiotechnol. 2018;16(1):71. 
3. Mothana RA. Evaluation of the in-vitro antiplasmodial, antileishmanial and antitrypanosomal activity of medicinal plants used in Saudi and Yemeni traditional medicine. Env Based Compl Alte Med. 2014.

4. Makhija K, Chandrashekar KS, Richard L, Jaykumar B. Phytochemical and pharmacological profile of Leucas lavandulaefolia: A review. Res $\mathrm{J}$ of Medi Plant. 2011;5(5):500-7.

5. Anonyomous. The Wealth of India: A Dictionary of Raw Materials and Industrial Products, Raw Materials, CSIR, New Delhi. 1962;6:80.

6. Yusuf M, Chowdhury JU, Waheb MA, Begum J. Medicinal Plants of Bangladesh, BCSIR, Dhaka. 1994;149-51.

7. Bhattacharya SK. Chiranjib Banousodhi, Part 2, Ananda Publisher Pvt. Ltd., Calcutta. 1995;234-63.

8. Mukherjee PK, Saha P, Perumal PSK, Saha BP. Preparation and evaluation of tincture of Leucas lavandulaefolia Reees (family-Labiatae) by cochemical and thin layer chromatography characteriazation. J Sci Ind Res. 1996;55(4):286-8.

9. Sastri B N. The Wealth of India: A Dictionary of Raw Materials and Industrial Products. Raw Materials, CSIR, New Delhi. 1962;3:64-6.

10. Manandhar NP. Plants and People of Nepal. Timber Press. Oregon. 2002.

11. Saha K, Mukherjee PK, Mandal SC, Pal M, Saha BP. Antibacterial activity of Leucas lavandulaefolia Rees.(Labiatae). Indian Drugs. 1995;32(8):402-4.

12. Saha K, Mukherjee PK, Pal M, Saha BP. Medicinal properties and chemical constituents of Leucas lavandulaefolia: A review. J of Medi Aro Plant Sci. 1997a;19:1045-8.

13. Shiraji AM. Studies on Leucas aspera. Indian J Pharm. 1947;19:116-7.

14. Bhattacharya S, Chiranjib B. Ananda Publishers Pvt. Ltd., Calcutta. 1995;23463.

15. Mukherjee PK, Saha K, Murugesan T, Mandal SC, Pal M. Screening of antidiarrhoeal profile of some plant extracts of a specific region of West Bengal, India. J Ethnopharmacol. 1998;60(1):85-9.

16. Mahato SB, Pal BC. Structure of linifoloside isopimarane rhamnoglucoside from Leucas linifolia. Phytochemistry. 1986;125:909-12.

17. Chandrashekar KS, Joshi AB, Satyarayanana D, Subramanyam VS. Flavonoid glycoside from Leucas lavandulaefolia. Ind J of Hete Chem. 2005;15(2):183-4.

18. Manandhar NP. Plants and People of Nepal. Timber Press. Oregon. 2002.

19. ICH Guideline Q2R1. Validation of Analytical Procedures: Text and Methodology, Geneva. 2005. http://www.ich.org.
20. Prabhu KS, Lobo R, Shirwaikar A. Free radical scavenging activity of aqueous extract of Spharanthus indicus (Linn.). Pharmacol. 2012;2:468-76.

21. Halliwell B, Gutteridge JMC, Aruoma OI. The deoxyribose method: A simple "test-tube" assay for determination of rate constants for reactions of hydroxyl radicals. Anal Biochem. 1987;165(1):215-9.

22. Cek J, Jurikova T, Skrovankova S, Sochor J. Quercetin and its anti-allergic immune response. Molecules. 2016;21(5):623.

23. Li J, Galley M, Brockett C, Spithourakis GP, Gao J, Dolan B. A persona-based neural conversation model. ArXiv Preprint ArXiv:1603.06155. 2016.

24. Morita M, Naito Y, Yoshikawa T, Niki E. Antioxidant capacity of blueberry extracts: Peroxyl radical scavenging and inhibition of plasma lipid oxidation induced by multiple oxidants. J Berry Res. 2017;7(1):1-9.

25. Pekkarinen SS, Heinonen IM, Hopia IA. Flavonoids quercetin, myricetin, kaempferol and (+)-catechin as antioxidants in methyl linoleate. J Sci of Food and Agri. 1999;79(4):499-506.

26. Morel I, Lescoat G, Cogrel P, Sergent O, Pasdeloup N, Brissot P. Antioxidant and iron-chelating activities of the flavonoids catechin, quercetin and diosmetin on iron-loaded rat hepatocyte cultures. Biochem Pharmacol. 1993;45(1):13-9.

27. Jimenez M, Garcia CF. Myricet in: An antioxidant flavonol is a substrate of polyphenol oxidase. J Sci of Food and Agri. 1999;79(14):1993-2000.

28. Kaurinovic B, Vastag D. Flavonoids and Phenolic Acids as Potential Natural Antioxidants. In Antioxidants. 2019. Intech Open.

29. Cos P, Ying L, Callome M, Hu JP, Cimanga K, Poel BV. Structure activity relationship and classification of flavonoids as inhibitors of xanthine oxidase and superoxide scavengers. J of Nat Prod. 1998;61(1):71-6.

30. Ramani R, Sudini S, Boddupalli BM, Anisetti RN. Antioxidant free radical scavenging and in-vitro cytotoxic studies of ethanolic extract of Leucas indica var Lavanduli folia and Leucas indica var Nagalapuramiana. Asian Pacif J of Trop Biomed. 2012;2(3):1637-42.

31. Sabri G, Vimala Y. Antibacterial and antioxidant activity of Leucas aspera flowers from bihar, india. Asian J of Pharmaceand Clin Res. 2018;11(2):223-6.

32. Shukla PK, Misra A, Srivastava S, Rawat AKS. Reversed Phase High Performance Liquid Chromatographic Ultra violet (Photo Diode Array) Quantification of Oleanolic Acid and its Isomer Ursolic Acid for Phytochemical Comparison and Pharmacological Evaluation of Four Leucas Species Used in Ayurveda. Pharmaco Mag. 2016;12(Supplement 2):S159.

\section{PICTORIAL ABSTRACT}
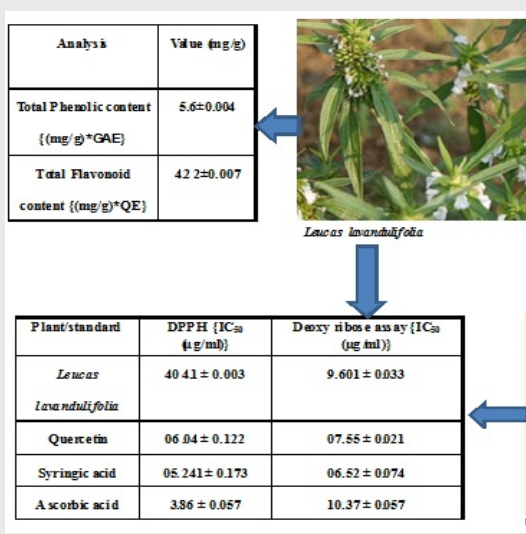

A scorbic aci
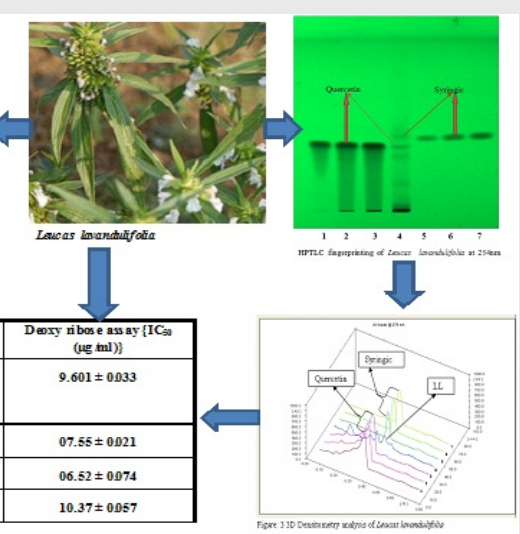

\section{SUMMARY}

- Phytochemicals are found within the standard limit of Ayurvedic Pharmacopoea of India.

- Identification of phenolic bioactive compounds.

- Development of HPTLC method for the quantification of pharmacologically active metabolite i.e. quercetin and syringic acid.

- Promising in-vitro antioxidant potential were observed in the L. lavandulifolia.

\section{About Authors}

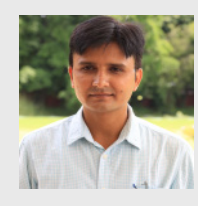

Dr. Pushpendra Kumar Shukla is working as Young Scientist \& Pl, in Pharmacognosy division, CSIR- National Botanical Research Institute, Lucknow, INDIA. He is working in the area of analytical chemistry on medicinal plants, chemotaxonomy, isolation of active metabolites and handling of sophisticated instruments like HPTLC, HPLC, OPLC, AAS and Column chromatography for identification and quantification of metabolites. He has 21 publications in peer reviewed journals 
Mrs. Akanksha Srivastava is working as Senior Research Fellow (ICAR-SRF), in Pharmacognosy Division at CSIR-National Botanical Research Institute; Lucknow, INDIA. She is working in the area of analytical chemistry on medicinal plants, In vitro study, chemotaxonomy, handling major analytical instruments including HPLC, HPTLC and column chromatography for quality control of herbal drugs. She has 05 publications in peer reviewed journals.

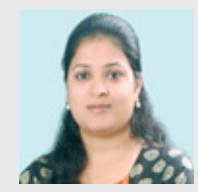

Dr. Ankita Misra is working as Young Scientist \& PI, in Pharmacognosy Division at CSIR-National Botanical Research Institute; Lucknow, INDIA. She is working in the area of analytical chemistry on medicinal plants, che $\neg$ motaxonomy, bio-prospection and natural product development, handling major analytical instruments including HPLC, HPTLC, OPLC and column chromatography for quality control of herbal drugs. She has 40 publications in peer reviewed journals and 1 patent is.

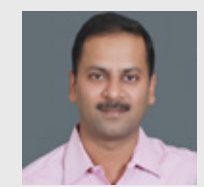

Dr. Sharad Srivastava is Senior Principal Scientist in Pharmacognosy Division at CSIR-National Botanical Research Institute; Lucknow, INDIA. He has made significant contributions to quality control of crude drugs/products, chemotaxonomy, bio-prospection and natural product development and have developed quality parameters of single crude drugs (more than 70 medicinal plants) and also identified biomarkers for their quality control. He has contributed 30 monographs of single herbal drugs in Ayurvedic Pharmacopoeia of India. He has 135 publi $\neg$ cations in peer reviewed journals, 17 patents and developed some technologies/formulations, few has already been transferred to industry.

Cite this article: Shukla PK, Srivastava A, Misra A, Srivastava S. Simultaneous Quantification of Quercetin and Syringic Acid in Methanolic Extract of Leucas lavandulifolia by using Validated HPTLC-Densitometric Method. Indian J of Pharmaceutical Education and Research. 2020;54(3s):s687-s694. 